\title{
SCIENTIFIC REP RTS \\ OPEN Author Correction: WNT-activated bone grafts repair osteonecrotic lesions in aged animals
}

B. Salmon ${ }^{1,2}$, B. Liu ${ }^{1}$, E. Shen ${ }^{1}$, T. Chen ${ }^{1,5}$, J. Li ${ }^{1,5}$, M. Gillette $^{1}$, R. C. Ransom ${ }^{1}$, M. Ezran ${ }^{1}$, C. A. Johnson ${ }^{1,6}$, A. B. Castillo ${ }^{3}{ }^{3}$, W. J. Shen ${ }^{4}$, F. B. Kraemer ${ }^{4}$, A. A. Smith ${ }^{1}$ \& J. A. Helms ${ }^{1}$

Correction to: Scientific Reports https://doi.org/10.1038/s41598-017-14395-9, published online 27 October 2017

The Acknowledgements section in this Article is incorrect.

“The authors would like to thank T. Doyle at Stanford's Live Imaging Center for his guidance, advice, and generous support for this project. This work was funded in part by a grant from CIRM (TR1-01249) to J.A.H., gift funds to Stanford University and supported by grant from the Philippe Foundation to B.S."

should read:

"The authors would like to thank T. Doyle at Stanford's Live Imaging Center for his guidance, advice, and generous support for this project. This work was funded in part by a grant from CIRM (TRAN1-09270) to Ankasa Regenerative Therapeutics, Inc., gift funds to Stanford University and supported by grant from the Philippe Foundation to B.S."

(c) (i) Open Access This article is licensed under a Creative Commons Attribution 4.0 International License, which permits use, sharing, adaptation, distribution and reproduction in any medium or format, as long as you give appropriate credit to the original author(s) and the source, provide a link to the Creative Commons license, and indicate if changes were made. The images or other third party material in this article are included in the article's Creative Commons license, unless indicated otherwise in a credit line to the material. If material is not included in the article's Creative Commons license and your intended use is not permitted by statutory regulation or exceeds the permitted use, you will need to obtain permission directly from the copyright holder. To view a copy of this license, visit http://creativecommons.org/licenses/by/4.0/.

(C) The Author(s) 2018
${ }^{1}$ Division of Plastic and Reconstructive Surgery, Department of Surgery, Stanford School of Medicine, Stanford, CA, USA. ${ }^{2}$ Paris Descartes University - Sorbonne Paris Cité, EA 2496 - Orofacial Pathologies, Imaging and Biotherapies Lab and Dental Medicine Department, Bretonneau Hospital, HUPNVS, AP-HP, Paris, France. ${ }^{3}$ Department of Mechanical and Aerospace Engineering, New York University Polytechnic School of Engineering, Brooklyn, NY, USA. ${ }^{4}$ Division of Endocrinology, Gerontology and Metabolism, Stanford University School of Medicine, Veterans Affairs Palo Alto Health Care System, Palo Alto, CA, USA. ${ }^{5}$ Present address: State Key Laboratory of Oral Diseases, West China Hospital of Stomatology, Sichuan University, Chengdu, China. ${ }^{6}$ Present address: Department of Plastic Surgery, University of Pittsburgh Medical Center, Pittsburgh, PA, USA. Correspondence and requests for materials should be addressed to J.A.H. (email: jhelms@stanford.edu) 